\title{
Achieving superior superplastic properties in fine grained intermetallic alloys based on $\gamma-\mathrm{TiAl}+\alpha_{2}-\mathrm{Ti}_{3} \mathrm{Al}$
}

\author{
V.M. Imayev ${ }^{\dagger}$, R. M. Imayev, T. I. Nazarova, R. A. Gaisin, A. A. Ganeev \\ †vimayev@mail.ru
}

Institute for Metals Superplasticity Problems of RAS, 39 Khalturin str., Ufa, 450001, Russia

\begin{abstract}
The present paper is a brief review of superplastic behavior of intermetallic alloys based on $\gamma$-TiAl $+\alpha_{2}-\mathrm{Ti}_{3} \mathrm{Al}$ with varying niobium content and refined microstructure obtained by hot working. Three $\gamma+\alpha_{2}$ alloys having the nominal compositions Ti-44.2Al-1.9Cr-0.7Nb-0.4B, Ti-45Al-8Nb-0.2C and Ti-43.7Al-4.2Nb-0.5Mo-0.2B-0.2C (at. \%) are considered in the paper. The hot working included quasi-isothermal hot forging or extrusion in the $\alpha+\gamma$ or $\alpha+\beta(\mathrm{B} 2)+\gamma$ phase field and hot forging at $T=950^{\circ} \mathrm{C}$. The hot working led to formation of refined partially rectystallized/globularized microstructures in the Ti- $44.2 \mathrm{Al}-1.9 \mathrm{Cr}-0.7 \mathrm{Nb}-0.4 \mathrm{~B}$ and $\mathrm{Ti}-43.7 \mathrm{Al}-4.2 \mathrm{Nb}-0.5 \mathrm{Mo}-0.2 \mathrm{~B}-0.2 \mathrm{C}$ alloys and fully ultrafine grained microstructure in the Ti-45Al-8Nb-0.2C alloy. The fine grained materials were used to prepare specimens for tensile testing. The tensile tests were performed at $T=800-1000^{\circ} \mathrm{C}$ and $\dot{\varepsilon} \sim 10^{-4}-10^{-3} \mathrm{~s}^{-1}$ in air without any protection against oxidation. Superplastic elongations and higher values of the strain rate sensitivity coefficient $(m>0.3)$ were reached at $T=850-1000^{\circ} \mathrm{C}$ for all alloys under study. The comparison of the superplastic properties of the alloys suggests that superplastic elongations were significantly higher owing to more intensive hot working and in the alloys with higher niobium content and volume fraction of the $\alpha_{2}$ phase. Microstructure examination showed that the last two factors provided slow dynamic grain growth during superplastic flow leading to sustainable superplastic flow and superior superplastic elongations $(\delta>1000 \%)$ in the Ti-43.7Al-4.2Nb-0.5Mo-0.2B-0.2C and Ti-45Al-8Nb-0.2C alloys. Particularly, incredible high superplastic elongations $(\delta=1270-2860 \%)$ were attained in the Ti-43.7Al-4.2Nb-0.5Mo-0.2B- $0.2 \mathrm{C}$ alloy at $T=900-1000^{\circ} \mathrm{C}$. The obtained results show that slow dynamic grain growth during superplastic flow is the key precondition for achieving superior superplastic properties in fine grained $\gamma+\alpha_{2}$ alloys.
\end{abstract}

Keywords: titanium aluminides, hot working, fine grained microstructure, superplasticity.

\section{Introduction}

It is now 30 years since the first paper devoted to superplasticity of intermetallic alloys based on $\gamma$-TiAl $+\alpha_{2}-\mathrm{Ti}_{3} \mathrm{Al}$ (hereafter $\gamma+\alpha$ alloys) was issued [1]. Later a number of investigations on superplasticity in $\gamma-\mathrm{TiAl}+\alpha_{2}-\mathrm{Ti}_{3} \mathrm{Al}$ alloys has been carried out and published [2-37]. It has been believed that superplastic properties are improved: i) with refining the microstructure down to $d \sim 0.1 \mu \mathrm{m}$, ii) with increasing the $\alpha_{2}-\mathrm{Ti}_{3} \mathrm{Al}$ phase content, iii) at transition from "conventional" peritectically solidifying alloys to $\beta$-solidifying ones, which are chemically more homogeneous, iv) with appearance of the $\beta$ (B2) phase, which is regarded to be favorable for superplasticity. However, it should be observed that the highest superplastic properties $(\delta>1000 \%)$ in $\gamma+\alpha_{2}$ alloys have been recently reached for the alloy with a low content of the $\alpha_{2}$ phase and free of the $\beta$ (B2) phase [36] and for the alloy with partially recrystallized microstructure containing $40 \%$ of lamellae remnants and near free of the $\beta$ (B2) phase [37]. It seems that there is non-obvious reason, which is more important for achieving superior superplastic properties in intermetallic $\gamma+\alpha_{2}$ alloys.

Theoretical models based on grain boundary sliding accommodated by dislocation glide and climb lead to a well known relationship [38]:

$$
\dot{\varepsilon}=A G b / k T(b / d)^{p}(\sigma / G)^{n} D_{0} \exp (-Q / R T),
$$

where $A$ is a dimensionless constant having a value of $\sim 10$, $G$ is the shear modulus, $b$ is the Burgers vector, $k$ is the Boltzmann's constant, $T$ is the absolute temperature, $d$ is the grain size, $p$ is the constant equal to $2-3, n$ is the stress exponent, which is the inverse of the strain rate sensitivity coefficient $m, Q$ is the activation energy, $R$ is the gas constant. As a rule, a decrease in the grain size leads to a decrease of the activation energy and therefore the grain refinement is the most effective way to enhance the superplastic strain rate. On the other hand, the ultrafine grained material possesses high susceptibility to dynamic grain growth during superplastic flow. A fast grain growth causes a decrease of contribution of grain boundary sliding to the superplastic deformation. In its turn, this leads to a decrease of the superplastic strain rate impeding achievement of superior superplastic elongations. One may assume that slow grain growth during superplastic flow is a very important prerequisite for achieving sustainable superplastic flow and superior superplastic properties, which is not directly reflected in equation (1). It is well known that dynamic grain growth is slower in the presence of a second phase. In respect of intermetallic $\gamma+\alpha_{2}$ alloys, the grain growth during superplastic flow is probably determined by alloying elements. The $\gamma$ and $\alpha$ phases have a wide homogeneity region and can dissolve a large amount of elements reducing diffusivity e.g. niobium [39-43]. Alloying with niobium increases considerably the activation energy of 
diffusion in the $\gamma$ and $\alpha_{2}(\alpha)$ phases [44-46] and improves oxidation resistance $[39,42,45]$. Therefore, alloying with niobium of $\gamma+\alpha_{2}$ alloys may be used for stabilizing a fine grained microstructure during superplastic flow.

The present paper is a brief review of superplastic behavior of $\gamma+\alpha_{2}$ alloys with varying niobium content and refined microstructure obtained by hot working [19, 36, 37]. The aim of the paper was to show the effect of the dynamic grain growth on superplastic behavior of $\gamma+\alpha_{2}$ alloys.

\section{Materials and experimental}

Three $\gamma+\alpha_{2}$ alloys were taken as starting materials. The Ti-44.2Al-0.7Nb-1.9Cr-0.4B alloy was produced by the induction skull melting technique and supplied from OAO "VILS", Russia as ingots with a diameter of $75 \mathrm{~mm}$. The Ti-45Al-8Nb-0.2C and Ti-43.7Al-4.2Nb-0.5Mo-0.2B-0.2C alloys were manufactured by vacuum arc remelting and supplied from GfE Metalle und Materialien, Germany as extruded rods of $\varnothing 48 \times 90 \mathrm{~mm}$ and cast ingots of $\varnothing 95 \times 180 \mathrm{~mm}$, respectively. Table 1 represents the processing conditions applied to produce refined microstructures in the alloys. For the sake of simplicity, the alloys under study are designated throughout the text as alloys $1-3$.

The alloys were subjected to two-stage hot working. The first stage included quasi-isothermal canned forging or extrusion in the $\alpha+\gamma$ or $\alpha+\beta(\mathrm{B} 2)+\gamma$ phase field and the second stage included isothermal forging at $T=950^{\circ} \mathrm{C}$. Sound forgings free of any cracks were manufactured. Thus, the hot work imparted during hot working was different. The highest total strain value was imparted in the case of alloy $3(e \approx 4)$, a lower strain value was imparted in the case of alloy 2 $(e \approx 3.55)$ and the lowest one was in the case of alloy $1(e \approx 1.2)$.

The obtained forged materials were used to prepare the specimens for tensile testing. Flat specimens with a gauge size of $10 \times 5 \times 2 \mathrm{~mm}^{3}$ were tensile tested at $T=800-1000^{\circ} \mathrm{C}$ with an initial strain rate of $\dot{\varepsilon}=10^{-3} \mathrm{~s}^{-1}$ (alloy 1) or $\dot{\varepsilon}=8.3 \times 10^{-4} \mathrm{~s}^{-1}$ (alloys 2 and 3 ). The tensile axis was always oriented perpendicular to the last forging direction. The tensile tests were performed in air without any protection against oxidation.
Microstructural examination was carried out using scanning electron microscopy in backscattering electron mode (SEM, BSE). Before study by SEM, the specimen surfaces were polished. The specimens for SEM examination were prepared from the grip area and near the fracture zone of the tensile tested specimens. BSE images were used to define the volume fractions of remnant lamellar colonies and the $\alpha_{2}$ phase, as well the mean grain size, $d$ in the grips and the gauge areas of the tensile deformed specimens. The volume fraction of the $\alpha_{2}-\mathrm{Ti}_{3} \mathrm{Al}$ phase was defined taking into consideration the globularized microstructures obtained after superplastic deformation.

\section{Results and discussion}

\subsection{Effect of processing on microstructure}

Alloy 1. Fig. 1a,b represents BSE images of the alloy in as-cast condition and after two-stage hot forging. The as-cast condition had a lamellar microstructure with a mean colony size of $d=90 \mu \mathrm{m}$. The volume fraction of the $\alpha_{2}-\mathrm{Ti}_{3} \mathrm{Al}$ phase was around $15 \%$, the $\beta$ (B2) phase was not detected. In the microstructure there were borides, which were located both along colony boundaries and within colonies. The two-stage hot forging led to partially globularized microstructure resulted from dynamic recrystallization and globularization processes during forging. The volume fraction of globularized microstructure was about 30\%, the remnants of lamellar colonies occupied about $70 \%$ [19]. Forging resulted in alignment of lamellae, which were oriented near perpendicular to the forging direction (Fig. 1b). The sizes of recrystallized $\gamma$ grains and $\alpha_{2}$ particlies were mostly in the range of $d=3-4 \mu \mathrm{m}$ and $0.5-2 \mu \mathrm{m}$, respectively. The borides after hot forging were broken down and had equiaxed or elongated form; their length was less than $15 \mu \mathrm{m}$.

Alloy 2. In the as-cast condition the alloy had a coarse near lamellar microstructure with a colony size of $d \sim 500-1000 \mu \mathrm{m}$. The fraction of the $\alpha_{2}-\mathrm{Ti}_{3} \mathrm{Al}$ phase was found to be around $3 \mathrm{vol} \%$, the $\beta$ (B2) phase was not detected [36]. Fig. 2a, b represents BSE images of the alloy

Table 1. Processing of the alloys under study [19, 36, 37].

\begin{tabular}{|c|c|}
\hline Alloy, at. \% & Processing ${ }^{\star}$ \\
\hline $\begin{array}{c}\text { Alloy } 1 \\
\text { Ti-44.2Al-0.7Nb-1.9Cr-0.4B }\end{array}$ & $\begin{array}{l}\text { i) Canned unidirectional forging under quasi-isothermal conditions } \\
\text { within the } \alpha+\gamma \text { temperature range }\left(\dot{\varepsilon}=10^{-2}-10^{-1} \mathrm{~s}^{-1}, e \approx 0.6\right) \text {; } \\
\text { ii) Intermediate annealing; } \\
\text { iii) Isothermal forging in the same direction at } T=950^{\circ} \mathrm{C}\left(\dot{\varepsilon} \sim 10^{-3} \mathrm{~s}^{-1}, e \approx 0.6\right) \text {; } \\
\text { iv) Ageing at } T=900^{\circ} \mathrm{C} \text {. }\end{array}$ \\
\hline $\begin{array}{c}\text { Alloy } 2 \\
\text { Ti-45Al-8Nb-0.2C }\end{array}$ & $\begin{array}{l}\text { i) Canned extrusion under quasi-isothermal conditions } \\
\text { within the } \alpha+\gamma \text { temperature range }\left(\dot{\varepsilon} \sim 10^{-1} \mathrm{~s}^{-1}, e \approx 1.95\right) \text {; } \\
\text { ii) Isothermal unidirectional forging at } T=950^{\circ} \mathrm{C}\left(\dot{\varepsilon} \sim 10^{-3} \mathrm{~s}^{-1}, e \approx 1.6\right) \text {; } \\
\text { iii) Ageing at } T=800^{\circ} \mathrm{C} \text {. }\end{array}$ \\
\hline $\begin{array}{c}\text { Alloy } 3 \\
\text { Ti-43.7Al-4.2Nb-0.5Mo-0.2B-0.2C }\end{array}$ & $\begin{array}{l}\text { i) Canned unidirectional forging under quasi-isothermal conditions } \\
\text { within the } \alpha+\beta(\mathrm{B} 2)+\gamma \text { temperature range }\left(\dot{\varepsilon}=10^{-2}-10^{-1} \mathrm{~s}^{-1}, e \approx 0.6\right) \text {; } \\
\text { ii) Intermediate annealing; } \\
\text { iii) Isothermal forging in the same direction at } T=950^{\circ} \mathrm{C}\left(\dot{\varepsilon} \sim 10^{-3} \mathrm{~s}^{-1}, e \approx 3.4\right) \text {; } \\
\text { iv) Ageing at } T=900^{\circ} \mathrm{C} \text {. }\end{array}$ \\
\hline
\end{tabular}


after hot extrusion and forging. A near fully fine grained microstructure was produced in the extruded material as a result of dynamic recrystallization and globularization processes. The sizes of $\gamma$ grains and $\alpha_{2}$ particles were in the range of $d=3-30$ and $0.5-2 \mu \mathrm{m}$, respectively. A striped microstructure with stripes parallel to the extrusion axis was observed after extrusion. Lamellae remnants elongated along the extrusion axis were sometimes distinguished. SEM examinations showed that the hot forging led to formation of a homogeneous near fully recrystallized ultrafine grained microstructure with a mean $\gamma$ grain $/ \alpha_{2}$ particle size of $d=0.9 \mu \mathrm{m}$ (Fig. 2b) [36].

Alloy 3. Fig. 3a, b represents BSE images of the alloy in as-cast condition and after two-stage hot forging. The cast material had a lamellar structure with a mean colony size of $d=63 \mu \mathrm{m}$. The volume fraction of the $\alpha_{2}-\mathrm{Ti}_{3} \mathrm{Al}$ phase was around $30 \%$, the volume fraction of the $\beta(\mathrm{B} 2)$ phase was defined as about $1 \%$. In the microstructure there were borides, which were located both along colony boundaries and within colonies. The hot forging led to development of dynamic recrystallization/globularization processes that resulted in a partially globularized microstructure with remnant heavily deformed lamellar colonies. SEM assessment showed that the volume fraction of globularized microstructure was about $60 \%$ (Fig. 1b). The mean size of globularized $\gamma$ grains and $\alpha_{2}$ particles was defined as $d=0.8 \mu \mathrm{m}$. The borides after hot forging were broken down and had equiaxed or elongated form; their length was not more than $10 \mu \mathrm{m}$.

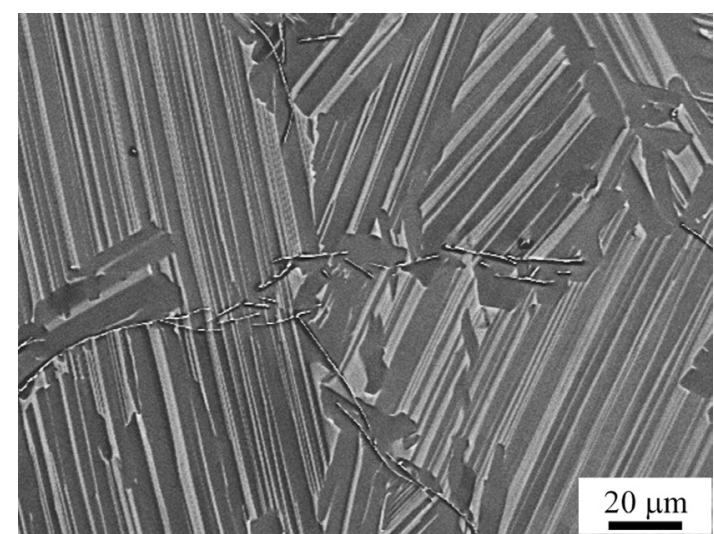

a

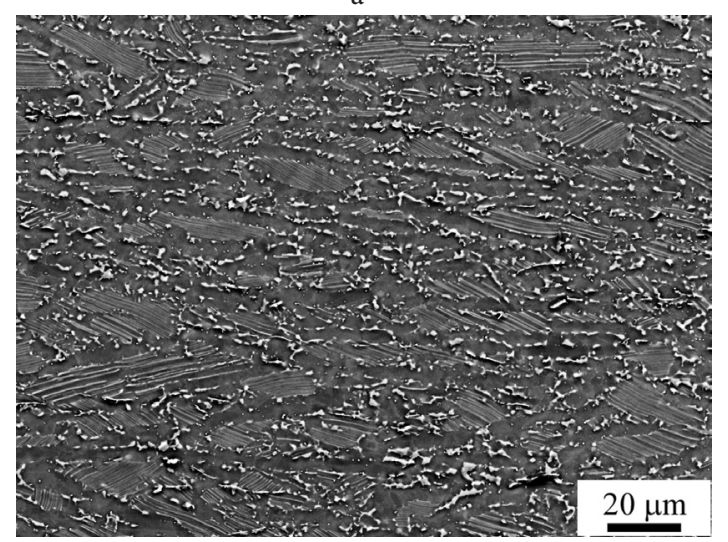

$\mathrm{C}$

\subsection{Superplastic properties}

Fig. 4 represents the temperature dependencies of elongation obtained for the hot worked alloys in the temperature range of $T=800-1000^{\circ} \mathrm{C}$. Note that testing at higher temperatures does not make sense in air because of intensive oxidation during long-term superplastic deformation, which impedes achieving superior superplastic elongations. This is especially so in the case of alloy 1 depleted by niobium. Even in alloy 2 containing 8 at. \%, the elongation decreased with increasing the test temperature from 1000 to $1050^{\circ} \mathrm{C}$ [36]. One can see that the elongations increased with increasing the test temperature reaching maximum values at $T=1000^{\circ} \mathrm{C}$. The highest elongations obtained for alloys 1, 2 and 3 were $\delta=775$, 1342 and $2780 \%$, respectively. The superplastic elongations at $T=850-1000^{\circ} \mathrm{C}$ corresponded to higher values of $m$ $(m>0.3)$ and low and near constant flow stresses (not shown here) typical of superplasticity $[19,36,37]$. This suggests that grain boundary sliding was the predominant deformation mechanism operating during superplastic deformation.

Thus, the superplastic properties of the alloys under study were significantly differed. Sustainable superplastic flow is dependent on different factors. The first of them is the "quality" of the refined microstructure. Clearly that refined microstructure with lamellae remnants is less preferable for superplasticity because grain boundary sliding will preferentially occur in the fine grained areas that can lead to the strain localization. From this point of view, the most favorable is alloy 2 , in which fully ultrafine

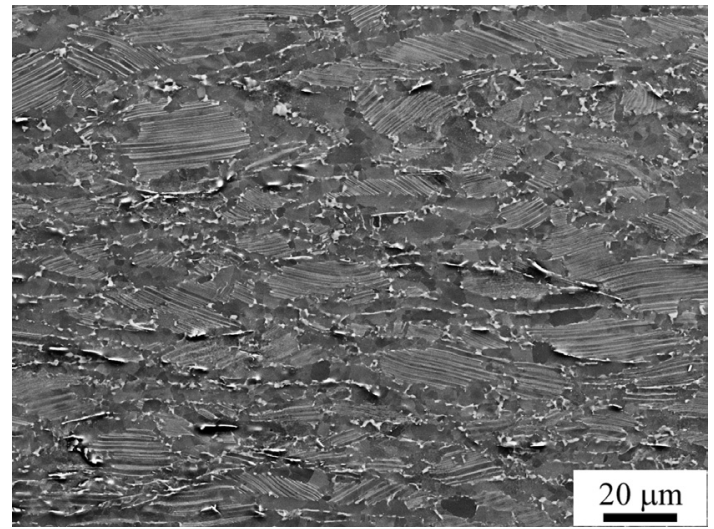

b

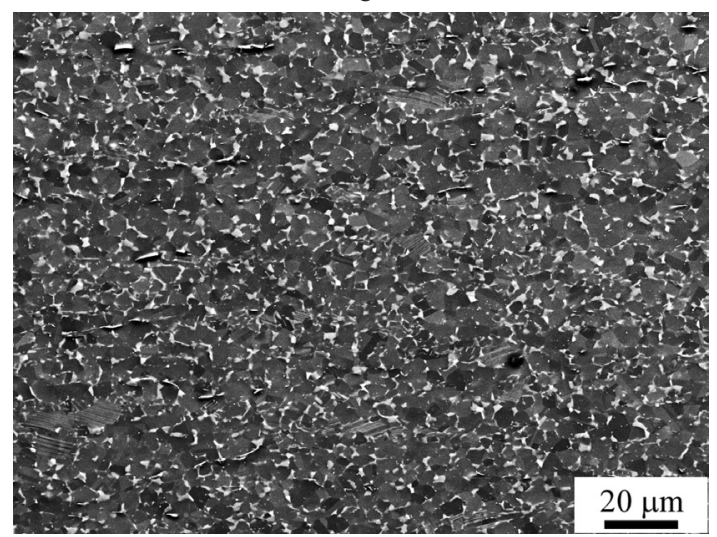

$\mathrm{d}$

Fig. 1. BSE images of alloy 1: the cast condition (a); after two-stage hot forging and ageing (b); after superplastic deformation at $T=1000^{\circ} \mathrm{C}$, $\dot{\varepsilon}=10^{-3} \mathrm{~s}^{-1}(\delta=775 \%)(\mathrm{c}, \mathrm{d})$; the grip area (c) and the gage area of the specimen near the fracture zone (d). 

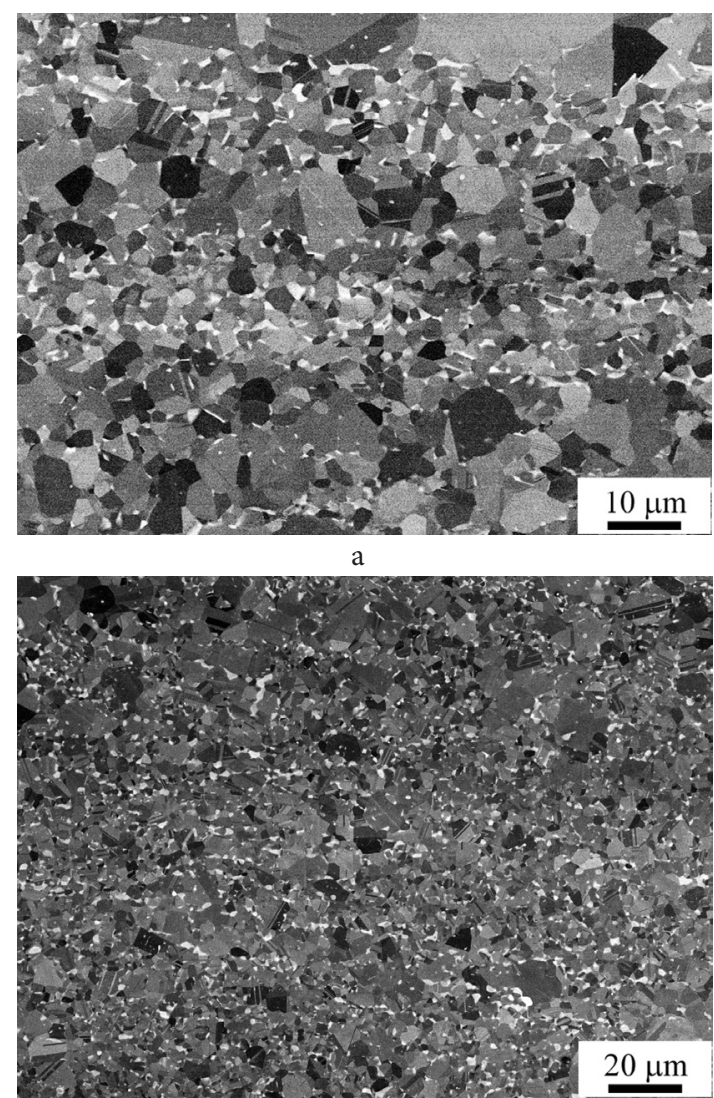

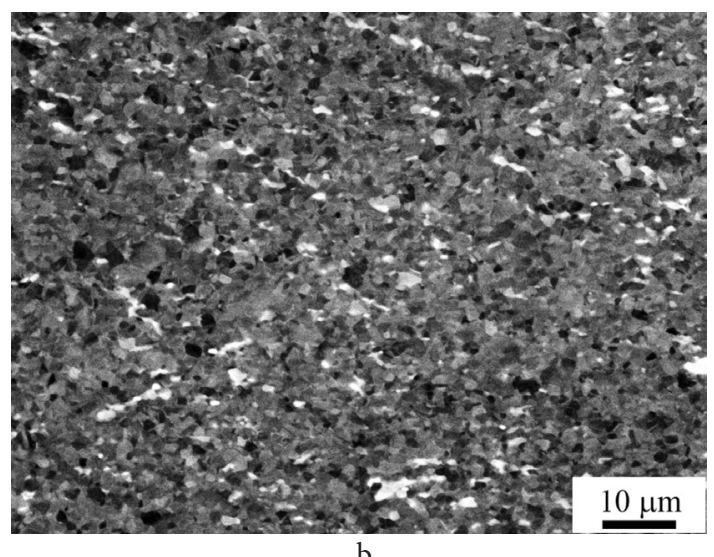

$\mathrm{b}$

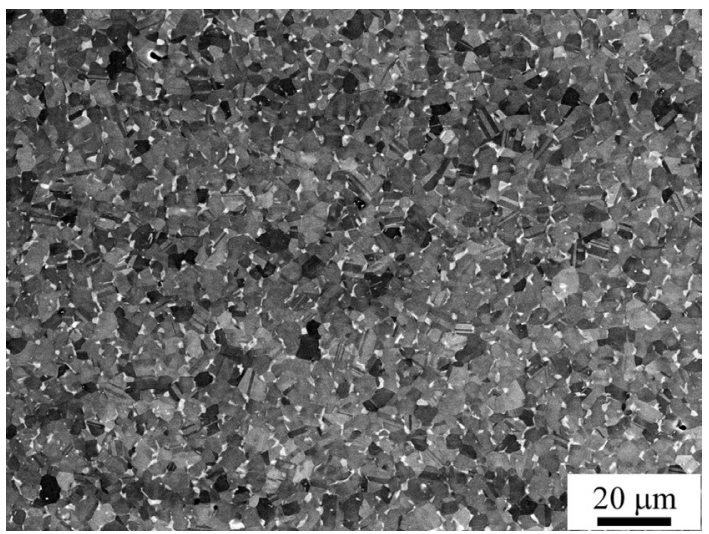

d

Fig. 2. BSE images of alloy 2 after: extrusion (the extrusion axis is horizontal) (a); extrusion and hot forging followed by ageing (b); superplastic deformation at $T=1000^{\circ} \mathrm{C}, \dot{\varepsilon}=8.3 \times 10^{-4} \mathrm{~s}^{-1}(\delta=1342 \%)(\mathrm{c}, \mathrm{d})$; the grip area (c) and the gage area of the specimen near the fracture zone (d).

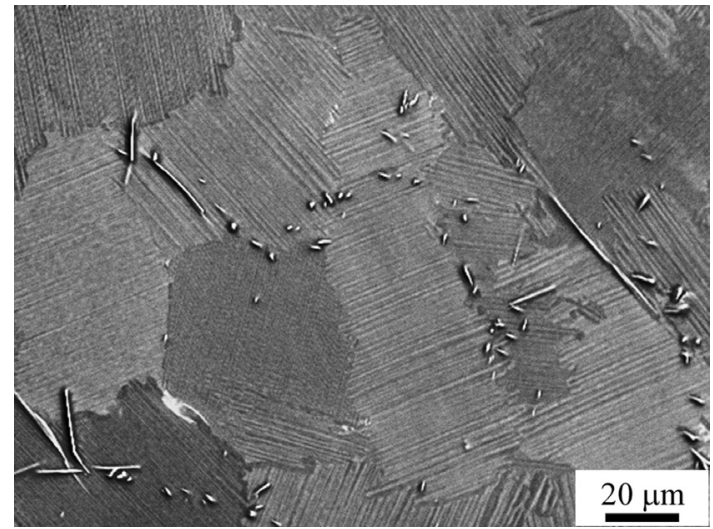

a

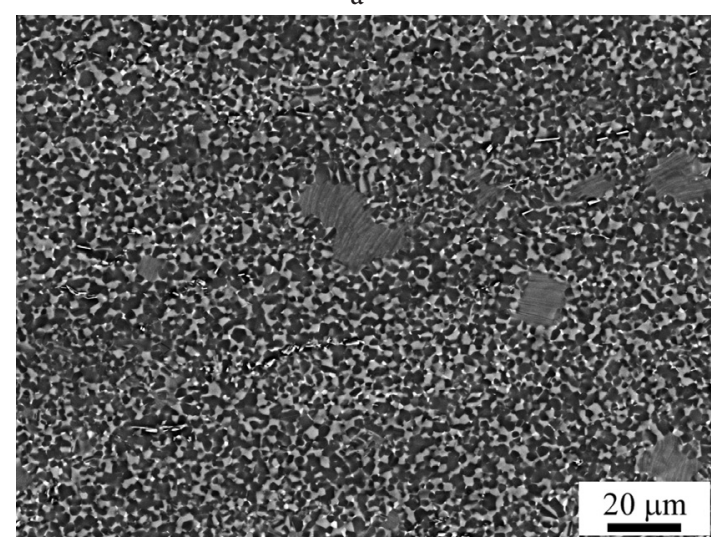

C

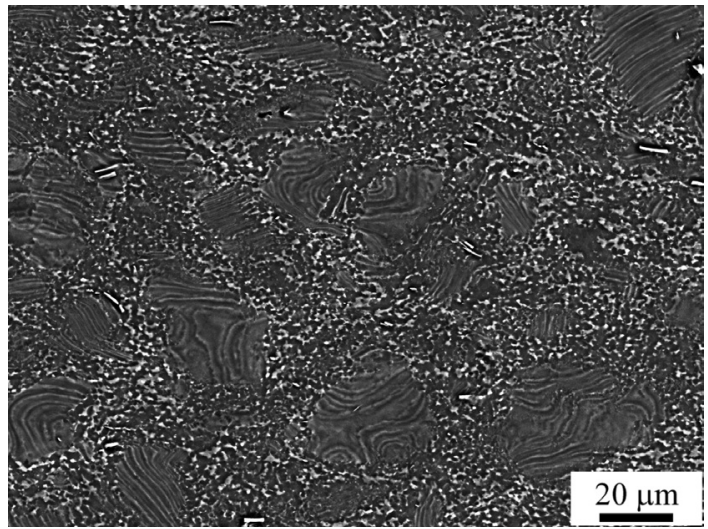

$\mathrm{b}$

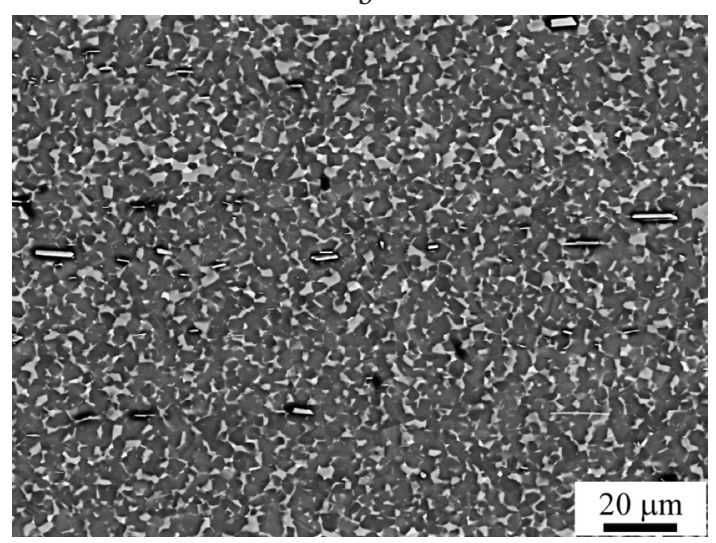

d

Fig. 3. BSE images of alloy 3: the cast condition (a); after two-stage hot forging and ageing (b); after superplastic deformation at $T=1000^{\circ} \mathrm{C}$, $\dot{\varepsilon}=8.3 \times 10^{-4} \mathrm{~s}^{-1}(\delta=2860 \%)(\mathrm{c}, \mathrm{d})$; the grip area (c) and the gage area of the specimen near the fracture zone (d). 


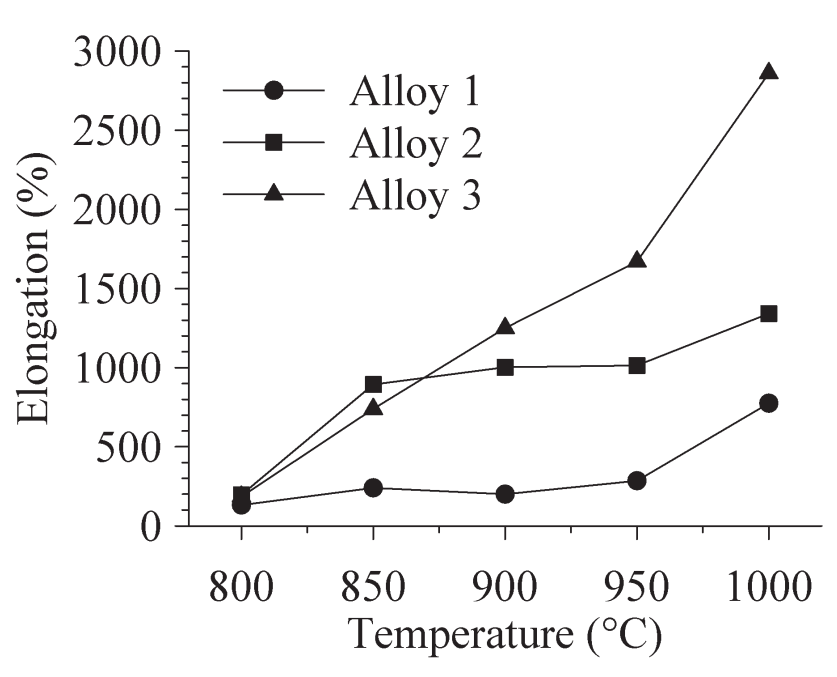

Fig. 4. The temperature dependences of total elongation, $\delta$, obtained for the alloys under study. The initial strain rate was $\dot{\varepsilon}=10^{-3} \mathrm{~s}^{-1}$ (alloy 1 ) or $\dot{\varepsilon}=8.3 \times 10^{-4} \mathrm{~s}^{-1}$ (alloys 2 and 3 ).

grained microstructure with predominantly high-angle grain boundaries was obtained [36]. On the other hand, in the case of a large strain imparted during hot working, dynamic recrystallization and globularization processes can extensively occur during superplastic flow leading to fast globularization of lamellae remnants. Alloy 3 was subjected to higher strain during forging procedure, whereas the strain value imparted in the case of alloy 1 was significantly smaller. Therefore, from the viewpoint of the microstructural "quality" alloy 2 looks preferential, then goes alloy 3 and 1 . The second factor is the phase composition. As mentioned, the presence of a large amount of the second $\alpha_{2}$ phase is preferable to retain refined microstructure during superplastic flow. Alloys 3 and 1 are more preferable from this point of view. The third factor may be associated with the alloy composition. Niobium is known to reduce diffusivity that can exert an influence on dynamic grain growth during superplastic flow.

Microstructural examination of the superplastically deformed specimens was carried out to explain the obtained superplastic properties.

\subsection{Microstructural changes after superplastic flow}

Table 2 shows microstructural changes after superplastic deformation at $T=1000^{\circ} \mathrm{C}$ observed in the grip and gauge areas of the tensile strained specimens. One can see that the microstructures were changed after tensile testing both in the grip and the gauge areas of the alloys. In the grip areas, the grain growth and transformation of remnant lamellar colonies into the fine grained structure occurred as a result of static recrystallization and globularization during testing. Superplastic deformation led to dynamic recrystallization and globularization processes and dynamic grain growth in the gauge sections of the samples. Even in alloy 1 having only about 30 vol. \% of the globularized microstructure before testing, superplastic deformation led to near fully recrystallized microstructure. Comparing the $\gamma$ grain $/ \alpha_{2}$ particle sizes of the alloys after superplastic deformation at $T=1000^{\circ} \mathrm{C}$ it is seen that alloy 3 retained much finer microstructure in contrast to alloy 2 and especially alloy 1 (Table 2). According to equation (1), this resulted in a decrease of the superplastic strain rate at transition from alloy 3 to alloy 2 and 1 .

It should be emphasized that the test duration was much longer in the case of alloy 3 as compared to alloy 2 and especially alloy 1 . Thus, the refined microstructure in alloy 3 was appreciably more stable against grain growth during superplastic deformation in contrast to alloys 2 and 1 . One may suggest that this was the key precondition for achieving superior superplastic properties in alloys 3 and 2 .

Thus, to achieve superior superplastic properties in fine grained $\gamma+\alpha_{2}$ alloys the following requirements should be met:

i) The hot working should be carried out in two stages. Firstly in the $\alpha+\beta(\mathrm{B} 2)+\gamma / \alpha+\gamma$ temperature field (depending on the alloy composition) to partially refine the cast microstructure and to increase the hot workability of the alloy. This allows the following forging at lower temperatures, in the $\alpha_{2}+\gamma$ or $\alpha_{2}+\beta(\mathrm{B} 2)+\gamma$ phase field. Moreover, as was shown for alloy 3 , multidirectional forging and large strains can be successfully realized in the $\alpha_{2}+\beta(\mathrm{B} 2)+\gamma$ temperature filed that undoubtedly promoted achieving superior superplastic

Table 2. Microstructural changes after superplastic deformation at $T=1000^{\circ} \mathrm{C}$ observed in the grip and gauge areas of the tensile strained specimens $\left(d_{\gamma}, d_{\alpha 2}, d_{\mathrm{gr}}\right.$ and $d_{\mathrm{g}}$ - the mean or typical sizes of recrystallized $\gamma$ grains/globularized $\alpha_{2}$ particles before testing, in the grip and gauge areas of deformed specimens, respectively; $V_{\text {glob }}-$ the volume fraction of the globularized microstructure).

\begin{tabular}{|c|c|c|c|c|c|c|}
\hline \multirow{2}{*}{ Alloy } & \multirow{2}{*}{$\begin{array}{l}\text { Strain } \\
\text { rate, } \\
\dot{\varepsilon}, \mathrm{s}^{-1}\end{array}$} & \multirow{2}{*}{$\delta, \%$} & \multirow{2}{*}{$\begin{array}{c}\text { Test } \\
\text { duration, } \\
\text { min }\end{array}$} & Microstructure & \multicolumn{2}{|c|}{ Microstructure after testing } \\
\hline & & & & $d_{\gamma / \alpha 2}, \mu \mathrm{m} / V_{\mathrm{glob}}, \%$ & $d_{\mathrm{gr}}, \mu \mathrm{m} / V_{\mathrm{glob}}, \%$ & $d_{\mathrm{g}}, \mu \mathrm{m} / V_{\mathrm{glob}}, \%$ \\
\hline 1 & $10^{-3}$ & 775 & 155 & $\begin{array}{c}d_{\gamma}=3-4, d_{\alpha 2}=0.5-2 \mu \mathrm{m} / \\
V_{\text {glob }} \approx 30 \%\end{array}$ & $\begin{array}{c}d_{\gamma}=4-5, d_{\alpha 2}=0.5-2 \mu \mathrm{m} / \\
V_{\mathrm{glob}} \approx 50 \%\end{array}$ & $\begin{array}{c}d_{\gamma}=5-7, d_{\alpha 2}=0.5-2 \mu \mathrm{m} / \\
V_{\mathrm{glob}} \approx 90 \%\end{array}$ \\
\hline 2 & $8.3 \times 10^{-4}$ & 1342 & 268.4 & $\begin{array}{c}d_{\gamma / \alpha 2}=0.9 \mu \mathrm{m} / \\
V_{\text {glob }} \approx 100 \%\end{array}$ & $\begin{array}{l}d_{\gamma / \alpha 2}=2 \mu \mathrm{m} / \\
V_{\mathrm{glob}} \approx 100 \%\end{array}$ & $\begin{array}{l}d_{y / \alpha 2}=3.15 / \\
V_{\text {glob }} \approx 100 \%\end{array}$ \\
\hline 3 & $8.3 \times 10^{-4}$ & 2860 & 572 & $\begin{array}{c}d_{\gamma / \alpha 2}=0.8 \mu \mathrm{m} / \\
V_{\text {glob }} \approx 60 \%\end{array}$ & $\begin{array}{c}d_{\gamma / \alpha 2}=1.7 \mu \mathrm{m} / \\
V_{\text {glob }} \approx 85 \%\end{array}$ & $\begin{array}{c}d_{\gamma / \alpha 2}=2.1 \mu \mathrm{m} / \\
V_{\text {glob }} \approx 95 \%\end{array}$ \\
\hline
\end{tabular}


elongations. The two-stage hot forging led to delocalized occurrence of recrystallization and globularization processes that provided obtainment of sound forgings with partially or fully recrystallized fine grained microstructure. Note that heavily deformed remnant lamellar colonies are not obstacles for achieving superplastic elongations even if the volume fraction of globularized microstructure is as low as $30 \%$. As was demonstrated, the remnant of lamellar colonies were recrystallized and globularized during superplastic deformation that most likely promoted achieving superior elongations impeding fast dynamic grain growth during superplastic flow.

ii) $\gamma+\alpha$ alloys highly alloyed with niobium are preferable. As follows from the obtained results, high alloying with niobium (along with increased content of the $\alpha_{2}$ phase) increased the microstructural stability of a fine grained condition during superplastic flow.

iii) The microstructural stability against grain growth during superplastic flow is also supported by a higher amount of the second $\alpha_{2}$ phase. As follows from the present study, $30 \mathrm{vol}$. $\%$ of the $\alpha_{2}$ phase was favorable for stability of the fine grained microstructure during superplastic flow and attaining high elongations.

iv) The $\beta$ (B2) phase content in $\gamma+\alpha$, based alloys should be minimized because this phase is too soft at elevated temperatures that leads to its smearing during superplastuc flow and impedes achieving superior superplastic elongations. Highest elongations attained in the $\gamma+\alpha_{2}+\beta$ (B2) alloys were mostly less than $700 \%$. The alloys under study showed elongations higher than $700 \%$ at $T=1000^{\circ} \mathrm{C}$ and were free (alloys 1 and 2) or near free (alloy 3 ) of the $\beta$ (B2) phase.

\section{Conclusions}

Superplastic behavior of three $\gamma+\alpha_{2}$ alloys, Ti-44.2Al-0.7Nb-1.9Cr-0.4B, Ti-45Al-8Nb-0.2C and Ti-43.7Al-4.2Nb-0.5Mo-0.2B-0.2C, was comparatively studied in the temperature range of $800-1000^{\circ} \mathrm{C}$. Prior tensile testing, the alloys were subjected to two-stage hot working including forging at a lower temperature $\left(T=950^{\circ} \mathrm{C}\right)$. The alloys showed significantly different superplastic elongations. The following preconditions for achieving superior superplastic properties in intermetallic $\gamma+\alpha_{2}$ alloys were proposed: i) the hot working should be carried out in two stages including at lower temperatures, in the $\alpha_{2}+\gamma$ or $\alpha_{2}+\beta(\mathrm{B} 2)+\gamma$ phase field. Multidirectional forging on the second stage is preferable; ii) a higher amount of the $\alpha_{2}$ phase and high alloying with niobium are favorable because this impedes the dynamic grain growth during superplastic flow; iii) the $\beta$ (B2) phase content should be minimized to exclude the strain localization within this phase during superplastic flow.

Acknowledgments. The work was supported by the Program of fundamental scientific researches of Governement Academy of Sciences No. AAAA-A17-117041310215-4. The work was performed using the facilities of the shared services center «Structural and Physical-Mechanical Studies of Materials» at the Institute for Metals Superplasticity Problems of Russian Academy of Sciences.

\section{References}

1. O. A. Kaibyshev. Czech.J. Phys. B 38, 395 (1988).

2. R. M. Imayev, V. M. Imayev. Scr. Met. 25, 2041 (1991).

3. T. Maeda, M. Okada, Y. Shida. Superplasticity in Advanced Materials, ed. by S. Hori, M. Tokizane and N. Furushiro. Jap. Soc. Res. Superplast. 311 (1991).

4. R.M. Imayev, O.A. Kaibyshev, G.A. Salishchev. Acta Metal. 40, 581 (1992).

5. S.C. Cheng, J. Wolfenstine, O.D. Sherby. Metal Trans. 23A, 1509 (1992).

6. W. B. Lee, H.S. Yang, W. Y- Kim, A. K. Mukherjee. Scr. Met. Mater. 29, 1403 (1993).

7. R.M. Imayev, G.A. Salishchev, V.M. Imayev, N.K. Gabdullin, M.R. Shagiev. Mater. Sci. Forum. 170 - 172, 453 (1994).

8. R.S. Mishra, W. B. Lee, A.K. Mukherjee. Gamma Titanium Aluminides, ed. by Y.-W. Kim, R. Wagner, M. Yamaguchi. The Minerals, Metals \& Mater. Soc. 571 (1995).

9. C.M. Lombard, A.K. Ghosh and S. L. Semiatin. Gamma Titanium Aluminides, ed. by Y.-W. Kim, R. Wagner, M. Yamaguchi. The Minerals, Metals \& Mater. Soc. 579 (1995).

10. R. Imayev, M. Shagiev, G. Salishchev, V. Imayev, V. Valitov. Scr. Mat. 34, 985 (1996).

11. V.M. Imayev, R.M. Imayev, G.A. Salishchev. Mater. Sci. Eng. A. 208, 226 (1996).

12. A. K. Mukherjee, R.S. Mishra. Mater. Sci. Forum. $243-245,609$ (1997)

13. T.G. Nieh, J. N. Wang, L.M. Hsiung, J. Wadsworth, V. Sikka. Scr. Mater. 37, 773 (1997).

14. V.M. Imayev, G.A. Salishchev, M.R. Shagiev, A. V. Kuznetsov, R. M. Imayev, O. N. Senkov, F. H. Froes. Scr. Mat. 40, 183 (1999).

15. R. M. Imayev, G. A. Salishchev, O. N. Senkov, V. M. Imayev, M.R. Shagiev, N. K. Gabdullin, A. V. Kuznetsov, F. H. (Sam) Froes. Mater. Sci. Eng. A. 300, 263 (2001).

16. F. Sun, D. Lin. Scr. Mater. 44, 665 (2001).

17. J. Sun, Y.H. He, J.S. Wu. Mater. Sci. Eng. A. 329-331, 885 (2002).

18. B. Zhang, J. N. Wang, J. Yang. Mater. Res. Bull. 7(14), 2315 (2002).

19. V.M. Imayev, R. M. Imayev A. V. Kuznetsov. Scr. Mat. 49, 1047 (2003).

20. V. M. Imayev, R. M. Imayev, A. V. Kuznetsov, M. R. Shagiev, G. A. Salishchev. Mater. Sci. Eng. A. 348, 15 (2003).

21. V.M. Imayev, R. M. Imayev, A. V. Kuznetsov. Gamma Titanium Aluminides, ed. by Y.-W. Kim, H. Clemens, A.H. Rosenberger. The Minerals, Metals \& Mater. Soc. 311 (2004).

22. Y. Wang, J. N. Wang, J. Yang. J. Alloys Compd. 364, 93 (2004).

23. D. Lin, F. Sun. Intermet. 12, 875 (2004).

24. J. A. Jiménez, O. A. Ruano, G. Frommeyer, S. Knippscher. Intermet. 13, 749 (2005).

25. J. N. Wang, Y. Wang. Int. J. Plast. 22, 1530 (2006).

26. V.M. Imayev, R.M. Imayev, T.I. Oleneva, T. G. Khismatullin. The Phys. Met. Metallogr. 106(6), 641 (2008). 
27. R. Safiullin, R. Imayev, V. Imayev, W. Beck, F. H. (Sam) Froes, G. Salishchev. Mater. Sci. Forum. $551-552,441$ (2007).

28. V.M. Imayev, T.G. Khismatullin, W. Beck, V. Guether, H.-J. Fecht. Scr. Mater. 57, 193 (2007).

29. C. Zhang, K. Zhang, G. Wang. Mater Lett. 63, 2153 (2009).

30. V. Imayev, R. Imayev, T. Khismatullin, T. Oleneva, V. Guhter, H.-J. Fecht. Mater. Sci. Forum. 638-642, 235 (2010).

31. C. Zhang, K. Zhang. J. Alloys Compd. 492, 236 (2010).

32. C. Qiu, Y. Liu, W. Zhang, B. Liu, X. Liang. Intermet. 27, 46 (2012).

33. H.Z. Niu, F. T. Kong, Y.Y. Chen, C. J. Zhang. J. Alloys Compd. 543, 19 (2012).

34. L. Cheng, Y. Chen, J. Li, E. Bouzy. Mater. Lett. 194, 58 (2017).

35. L. Cheng, J. Li, X. Xue, B. Tang, H. Kou, O. Perroud, E. Bouzy. J. Alloys Compd. 693, 749 (2017).

36. V. Imayev, R. Gaisin, A. Rudskoy, T. Nazarova, R. Shaimardanov, R. Imayev. J. Alloys Compd. 663, 217 (2016).

37. V. M. Imayev, A. A. Ganeev, R. M. Imayev. Intermet. 101,
81 (2018).

38. R.R. Mulyukov, R.M. Imayev, A.A. Nazarov, et al. Superplasticity of Ultrafine Grained Alloys: Experimental, Theory, Technologies. Nauka, Moscow (2014) 287 p. (in Russian)

39. F. Appel, R. Wagner. Mater. Sci. Eng. R. 22, 187 (1998).

40. U. Brossmann, M. Oehring, F. Appel. Structural Intermetallics 2001, ed. by K. J. Hemker, D. M. Dimiduk, H. Clemens et al. The Minerals, Metals \& Mater. Soc. 191 (2001).

41. S-C. Huang. Structural Intermetallics 1993, ed. by R. Darolia, J. J. Lewandowski, C. T. Liu et al. The Minerals, Metals \& Mater. Soc. 299 (1993).

42. J. D. H. Paul, F. Appel, R. Wagner. Acta Mater. 46, 1075 (1998).

43. R. Kainuma, Y. Fujita, H. Mitsui, I. Ohnuma, K. Ishida. Intermet. 8, 855 (2000).

44. Y. Mishin, Chr. Herzig. Acta Mater. 48, 589 (2000).

45. F. Appel, J. D. H. Paul, M. Oehring, U. Froebel, U. Lorenz. Metall. Mater. Trans. 34A, 2149 (2003).

46. Ch. Herzig, T. Przeorski, M. Friesel, F. Hisker, S. Divinski. Intermet. 9, 461 (2001). 